\title{
Particle Characterization of Washing Process Effluents by Laser Diffraction Technique
}

\author{
Mirjana Čurlin ${ }^{1}$, Tanja Pušić ${ }^{2, *(\mathbb{D})}$, Branka Vojnović ${ }^{2}(\mathbb{D})$ and Nino Dimitrov $^{3}$ (D) \\ 1 Faculty of Food Technology and Biotehnology, University of Zagreb, Pierottijeva 6, 10000 Zagreb, Croatia; \\ mcurlin@pbf.hr \\ 2 Faculty of Textile Technology, University of Zagreb, Prilaz baruna Filipovića 28a, 10000 Zagreb, Croatia; \\ branka.vojnovic@ttf.unizg.hr \\ 3 Department for General Use Items, Croatian Institute of Public Health, Rockefeller Str. 7, \\ 10000 Zagreb, Croatia; nino.dimitrov@hzjz.hr \\ * Correspondence: tanja.pusic@ttf.unizg.hr
}

Citation: Čurlin, M.; Pušić, T.; Vojnović, B.; Dimitrov, N. Particle Characterization of Washing Process Effluents by Laser Diffraction Technique. Materials 2021, 14, 7781. https://doi.org/10.3390/ma14247781

Academic Editor: Frank Lipnizki

Received: 10 November 2021 Accepted: 11 December 2021 Published: 16 December 2021

Publisher's Note: MDPI stays neutral with regard to jurisdictional claims in published maps and institutional affiliations.

Copyright: (c) 2021 by the authors. Licensee MDPI, Basel, Switzerland. This article is an open access article distributed under the terms and conditions of the Creative Commons Attribution (CC BY) license (https:// creativecommons.org/licenses/by/ $4.0 /)$.

\begin{abstract}
The dominant type of polymer particles in water, sediment, and various organisms partly derives from natural and synthetic fibres released in the washing process. Pollution of aquatic recipients with these particles poses an interdisciplinary problem throughout the world. Wastewater from washing represents a dispersion system with different particle sizes that is also loaded with the source of the particles. Due to this complex system, the qualification and quantification of this type of pollution is difficult. In this paper, the laser diffraction technique was applied to characterize particles in effluents from washing and rinsing materials made of a mixture of cotton and polyester. The results obtained through the analysis prove that the laser diffraction technique is acceptable for the characterization of a composite effluent sample. The advanced statistical technique of multivariate analysis confirmed the interrelationship of the parameters of this complex dispersion system.
\end{abstract}

Keywords: textiles matrix; washing; dispersion system; particles; particle size distribution; cluster analysis

\section{Introduction}

The improvement of the functionality of polymers, by affecting their physical, chemical and some biological (e.g., antimicrobial) properties, can be achieved by adding chemical additives [1]. The polymer matrix and the functional additive can be connected by a covalent bond or much weaker bonds, so their release in dry and wet treatments is expected. Additional release of particles during usage, such as fibrils and fragments from polymer materials, can affect environmental systems, where the released formations can be carriers of micro-/nano-particles of substances such as dyes, pigments, functional coatings, surfactants, preparations, softeners, and others.

The issue of fibril release is related to different areas of research and testing because the assessment of fibre transfer is of particular importance for the impact of the textile industry on the environment. The process of washing textiles in the household is identified as a significant cause of environmental pollution, where the release of particles from textiles is mainly due to chemical and mechanical influences in the washing process [2-7]. The influence of chemistry is attributed to the detergent containing inorganic and organic substances of different solubility that, in synergy with other factors of the Sinner's circle, fulfil the tasks in washing [8]. The fibrils, additives, and components of the detergent released during washing chemically and biologically load the composition of the effluent. As the material ages, the potential risk of migration of functional particles such as silver increases, which then reach the wastewater via the effluent from textile washing machines [9]. Particles released into wastewater treatment plants in this way, with an average inflow of $11 \mu \mathrm{g} / \mathrm{L}$, can inhibit the growth of microbial culture, reduce the efficiency of wastewater treatment, or become toxic to aquatic organisms by streaming into natural recipients $[10,11]$. 
The influence of mechanics on the release of polymer fibrils in washing, especially when it comes from textiles, has been a focus of the scientific community in the last few years [12]. The washing machine design type affects the hydrodynamics, the transport of textiles, and the baths inside the drum. Due to resistance forces that occur inside the rotating drum and article agitation, fibrils are released and migrated, thus loading the recipients [13].

The contamination of aquatic recipients with microplastic particles originates, in part, from synthetic fibres released during the washing process; it is known that synthetic fibres are the dominant type of polyester microplastic found in water, sediment, and various organisms [14,15].

Due to the potential contamination of aquatic recipients with different particles, it is important to characterize the wastewater from washing through determining the particle size [16-18].

In view of the above, washing wastewater can contain a significant quantity of solid phases and form a disperse system. Such particles are classified as dissolved, colloidal, fine, and settleable solids [19]. In wastewater treatment plants, large particles are removed by standard procedures in the primary treatment process, while reducing the concentration of small particles in wastewater poses a challenge in wastewater treatment and water reuse.

Determining the volumetric or numerical particle size distribution, known as particle size analysis (PSA) or particle size distribution (PSD), is an important parameter for the physicochemical or biological wastewater treatment of drinking water, municipal and industrial wastewater, and agricultural and natural waters [20-26].

The present research focuses on the analysis of effluents from the washing and rinsing process by applying the PSA method, as a contribution to the characterization of released particles from cotton/PES fabric in these processes, which has not yet been applied to these phenomena. From the obtained results, the influence of process parameters on particle release was estimated using the multivariate analysis (MVA) [27].

\section{Materials and Methods}

\subsection{Materials}

A fabric made of a mixture of cotton and polyester $(60 / 40)$, of surface mass $270 \mathrm{~g} / \mathrm{m}^{2}$, and density 37 threads in warp direction and 14 threads in weft direction was analysed. The fabric was woven in crepe weave through systematic adding of binding points in the plain weave. The finer warp and coarser weft were used. Crepe weaves produce a restless and grainy fabric appearance, Figure 1.

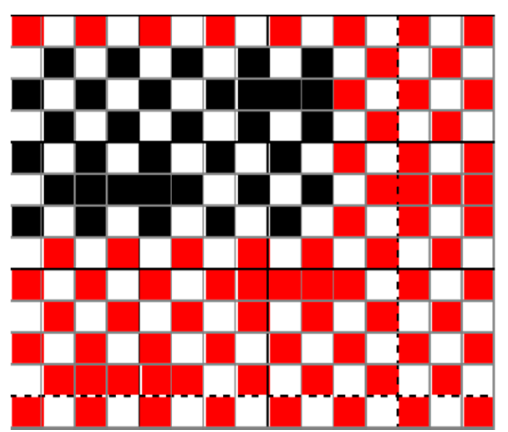

(a)

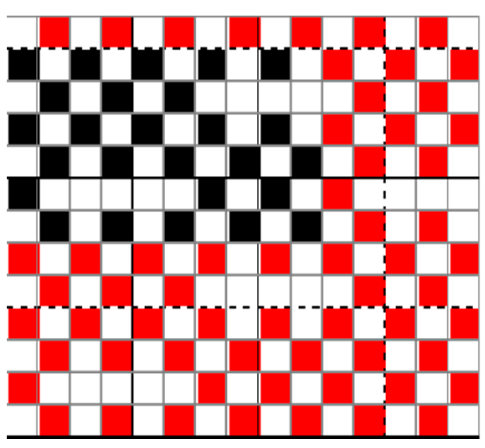

(b)

Figure 1. Fabric: (a) face side; (b) back side.

Samples of cotton/PES fabric were washed with water and ECE B detergent, the composition of which is shown in Table 1. 
Table 1. Composition of reference detergent ECE B.

\begin{tabular}{|c|c|}
\hline Ingredient & $\mathrm{w}(\%)$ \\
\hline Linear sodium alkylbenzene sulfonate (LAS) & 8.0 \\
\hline Ethoxylated fatty alcohol C12/18 (14EO) & 2.9 \\
\hline $\begin{array}{l}\text { Sodium soap (C 12-16: } 13-26 \% \text {. C 18-22: } \\
74-87 \% \text { ) }\end{array}$ & 3.5 \\
\hline Sodium triphosphate & 43.7 \\
\hline Sodium silicate $\left(\mathrm{SiO}_{2}: \mathrm{Na}_{2} \mathrm{O}=3.3: 1\right)$ & 7.5 \\
\hline Potassium silicate & 1.9 \\
\hline Carboxymethylcellulose (CMC) & 1.2 \\
\hline Ethylenediaminetetraacetic acid & 0.2 \\
\hline Sodium sulphate & 21.2 \\
\hline Water & 9.9 \\
\hline$\Sigma$ & 100 \\
\hline
\end{tabular}

\subsubsection{Washing and Rinsing Procedures}

Samples of fabric were washed in Polymat, W. Mathis, bath ratio (BR 1:5) at the standard programme at $90{ }^{\circ} \mathrm{C}$ with reference detergent ECE B at a concentration of $5 \mathrm{~g} / \mathrm{L}$ and water through 5 cycles for $30 \mathrm{~min}$.

After each cycle of washing with detergent and water, samples were rinsed in a laboratory beaker with water (BR 1:6) at $20^{\circ} \mathrm{C}$ through 5 cycles. The rinsed samples were air-dried.

\subsubsection{Sampling}

The collected composite effluents after 5 washing cycles with detergent and 25 rinsing cycles with water, as well as after 5 washing cycles with water and 25 rinsing cycles with water, were used for further analysis, as shown in Table 2.

Table 2. Designation of effluents.

\begin{tabular}{cccc}
\hline Washing & Effluent 1 & Rinsing & Effluent 2 \\
\hline ECE B detergent & D_sample 1 & Water & D_sample 2 \\
\hline Water & W_sample 1 & Water & W_sample 2 \\
\hline
\end{tabular}

The same samples were subjected to a membrane filtration procedure using filter from glass fibres with a pore size of $0.7 \mu \mathrm{m}$ and a diameter of $43 \mathrm{~mm}$. Filters with residual substances after drying in an oven at $105^{\circ} \mathrm{C}\left( \pm 5^{\circ} \mathrm{C}\right)$ were tested by staining and examined by digital microscope.

\subsection{Methods}

\subsubsection{Turbidity}

Turbidity of detergent solution and effluents (D_sample 1, D_sample 2, W_sample 1, W_sample 2) was measured by nephelometric method HRN EN ISO 7027-1: 2016. A turbidity meter Hach TL 2350 was calibrated with a certified reference material, STABLCAL (Stabilized Formazine Standard) and checked with the Gelex Secondary Turbidity Standards (GSTS).

\subsubsection{Particle Size Analysis (PSA)}

PSA is a laser diffraction technique in which the diffraction angle depends on the particle size, i.e., the pattern of diffraction of the sample is dependent on the particle size distribution, PSD. The outcome of the measurement is a particle size distribution function [28]. 
The results of the analysis are described as a density or frequency distribution $\left(q_{3}\right)$ indicating the probability of finding a particle diameter $\mathrm{D}$ in the population, and a cumulative curve $\left(Q_{3}\right)$ indicating the percentage of particles smaller or larger than diameter $\mathrm{D}$. The mathematical correlation of the cumulative and frequency curve is presented in the following Equation (1):

$$
Q_{3}(r)=\int_{0}^{r} q_{3}(r) d r
$$

A simple graphical interpretation of the curves provides satisfactory results. The particle size distribution curve is a statistical curve, that provide important data on particle parameters in the disperse system that can be mathematically determined. These parameters include: (i) mode; (ii) median or D50, which is the value separating the higher half of the data from the lower half, which can be easily determined from the cumulative distribution curve; (iii) mean, which is the most characteristic value of a sample. The laser diffraction technique using volume-weighted mean diameter and calculation of these means follows the equation:

$$
\mathrm{D}[4,3]=\frac{\sum n \cdot d^{4}}{\sum n \cdot d^{3}}
$$

Apart from the above statistical parameters, the most common values used in particle sizing technique are the $\mathrm{D}$-values, which means that generally $\mathrm{D}_{\mathrm{x}}$ presents the diameter, of which an x percentage of the particles is smaller. The three most frequently used Dvalues are $\mathrm{D}_{10}, \mathrm{D}_{50}$, and $\mathrm{D}_{90}$, but custom $\mathrm{D}$-values can be found for the characterization of samples.

A helpful description of the particle size distribution usually requires a method of describing the shape of the distribution. An important measure of any statistical distribution is the width or broadness. A frequently used measure in laser diffraction is the span. In general, it is calculated by the following equation:

$$
\text { Span }=\frac{D_{90}-D_{10}}{D_{50}}
$$

The Particle Size Analysis (PSA) was performed according to a standard measurement procedure for each sample in a series of three repetitions on a PSA 1190 LD Anton Paar $\mathrm{GmbH}$, Austria. The optimization of input parameters such as stirring and pump optimization allows one to obtain consistent and repeatable results. As a dispersion medium, water was used, and obscuration was 9-13\%; stirrer and pump speed were medium.

\subsubsection{Cluster Analysis}

Cluster analysis using TIBCO Statistics software was applied to evaluate different parameters of washing and rinsing impact on particles in effluents. This method is part of multivariate statistical analysis (MVA), which is used to analyze complex data sets and their relationships. We used this empirical method, which places similar objects that are close to each other in the space of variables into the same class, for the particle size distribution data of washing and rinsing treatments. The result is presented in the form of a dendogram of the stepwise combination of objects in clusters. The Euclidean distance defined by Equation (4) is the distance $d$ between two points in n-dimensional space with coordinates $x_{j}$ and $y_{j}$ [27].

$$
d_{x, y}=\sqrt{\sum_{j=1}^{J}\left(x_{j}-y_{j}\right)^{2}}
$$

\subsubsection{Characterisation of Filter Residues}

The solid residue on the filter was stained by soaking in cold solution of $2 \%$ Bezaktiv Brilliant Blau V-R spez. (C.I. Reactive Blue 19) from Bezema for $15 \mathrm{~min}$. Afterwards, filters 
were dried and examined with the digital microscope Dino-Lite Premier, IDCP under magnification of $50 \times$ and $230 \times$.

\section{Results and Discussion}

The source of solid particles in washing effluents can be textile material, detergent, or water, which makes it difficult to choose methods for their characterization. This research focused on the application of PSA in the analysis of effluents collected as composite samples from five washing cycles and 25 rinsing cycles of a cotton/PES fabric. The first effluent is from washing with standard detergent (D_sample 1), the second is from subsequent rinsing with water (D_sample 2), the third is from washing with water (W_sample 1), and the fourth is from subsequent rinsing with water (W_sample 2), Table 2.

Results of turbidimetric analysis of detergent solution and effluents are presented in Table 3.

Table 3. Turbidity of detergent solution and effluents.

\begin{tabular}{cc}
\hline Sample & Turbidity/NTU \\
\hline Detergent solution & 255.7 \\
\hline D_sample 1 & 64.2 \\
\hline W_sample 1 & 2.20 \\
\hline D_sample 2 & 20.4 \\
\hline W_sample 2 & 8.85 \\
\hline
\end{tabular}

The analysis of turbidity results in Table 3 shows the difference between washing and rinsing effluents. The turbidity value of detergent solution is 255.7 NTU and correlates with the composition shown in Table 1 . The turbidity of effluent D_sample 2 is three times lower than that of D_sample 1, while the turbidity of W_sample 2 is four times higher than that of W_sample 1 . The increase in turbidity may be influenced by fibril fragments. This hypothesis was underlined by the laser diffraction method as follows.

PSA was applied as the overlay of three consecutive measurements for the density distribution and the cumulative distribution as displayed in figures and tables. This is a common way of showing the particle size distribution where the function is obtained by applying Equation (1).

The results of the particle size distribution for the effluent from washing in detergent and subsequent rinsing are shown in Figures 2 and 3.

Based on the results of effluent analysis, the D-value was determined for particles smaller than 10, 50, and $90 \mu \mathrm{m}$. The results for mean values of $\mathrm{D}_{10}, \mathrm{D}_{50}, \mathrm{D}_{90}$, and Span which determine according to Equation (3) are shown in Table 4.

From the PSA results shown in Table 4 and Figures 2 and 3 for effluents from washing in detergent and subsequent rinsing, it can be seen that both samples belong to monodisperse systems, with the mean particle size and $D_{90}$ being smaller for the effluent from rinsing. A comparison of Span values calculated according to Equation (3) for both samples indicate differences in particle distribution by diameter. The Span value for the effluent from washing is 3657 , whereas for the effluent from rinsing it is 2661 . In this system, the detergent has a significant effect on the effluent load with particles, despite the fact that the rinsing process was carried out in water, i.e., without detergent.

The role of detergent in this "clean" system could not be for removing the soil, and it tends to load the material surface and, partly, the effluent. Therefore, the rinsing process removes most of the residual substances from the material, which puts a load on the effluent.

The results of the particle size distribution for the effluent from washing in water and subsequent rinsing are shown in Figures 4 and 5 and Table 5. 


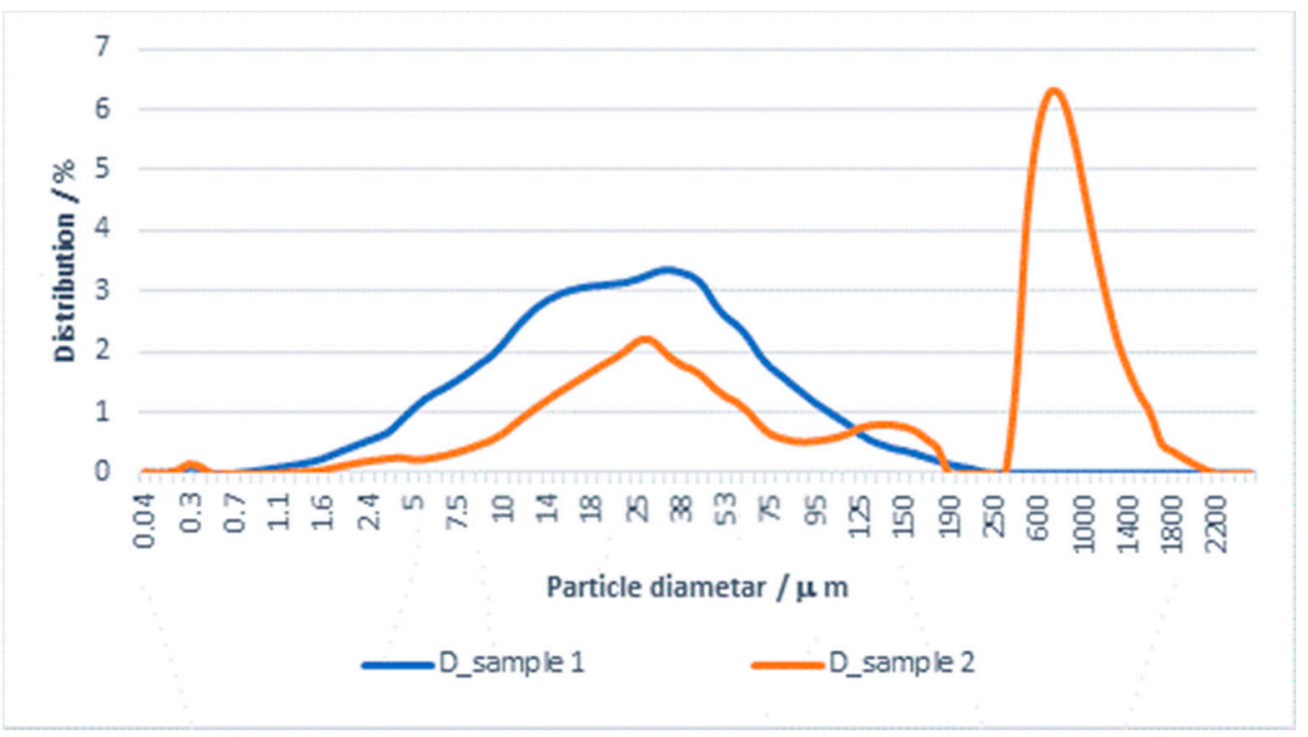

Figure 2. Distribution of particles (PSA) in effluent from washing a cotton/PES fabric with detergent and subsequent rinsing with water.

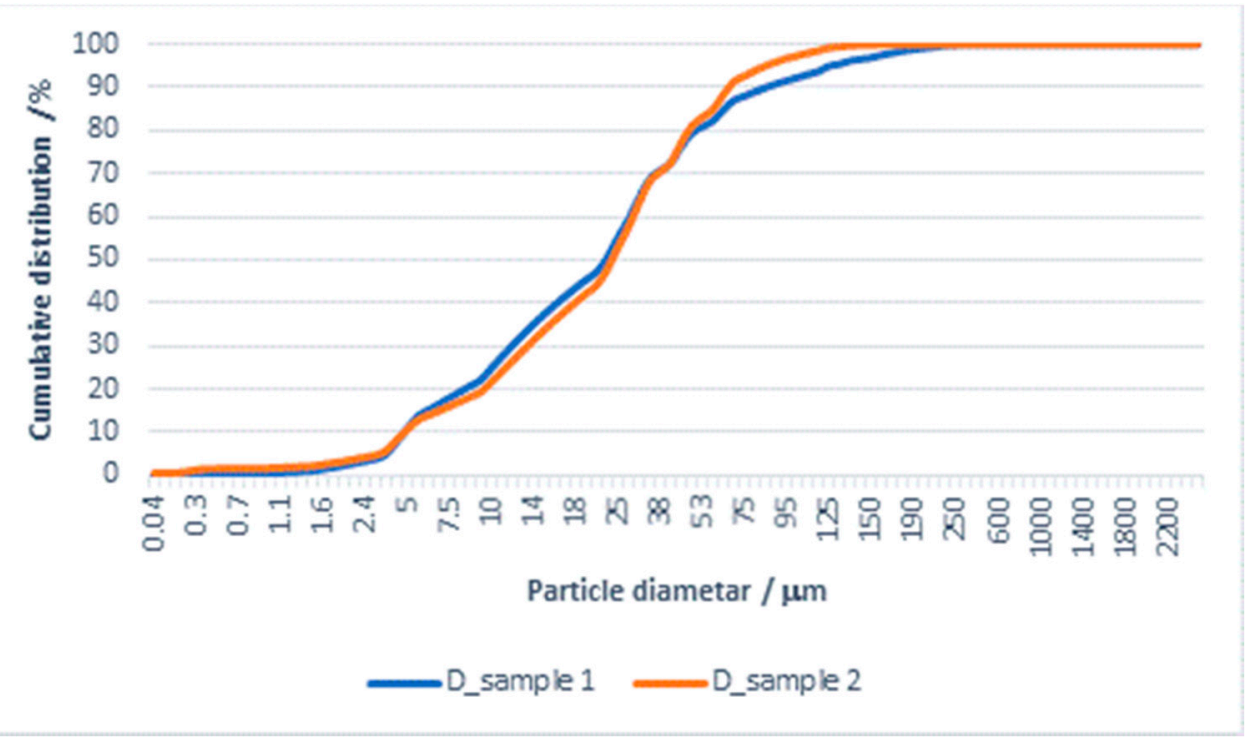

Figure 3. Cumulative distribution of particles (PSA) in effluent from washing a cotton/PES fabric with detergent and subsequent rinsing with water.

Table 4. Results of volume-weighted D-value for effluents from washing with detergent and rinsing.

\begin{tabular}{llllll}
\hline Mean Value $/ \mu \mathrm{m}$ & $\mathrm{D}_{\mathbf{1 0}} / \mu \mathrm{m}$ & $\mathrm{D}_{\mathbf{5 0}} / \boldsymbol{\mu m}$ & $\mathrm{D}_{\mathbf{9 0}} / \boldsymbol{\mu m}$ & Mean Size/ $\mathrm{mm}$ & Span \\
\hline D_sample 1 & 4.726 & 21.830 & 84.549 & 37.116 & 3.657 \\
\hline D_sample 2 & 4.935 & 23.968 & 68.710 & 33.027 & 2.661 \\
\hline
\end{tabular}




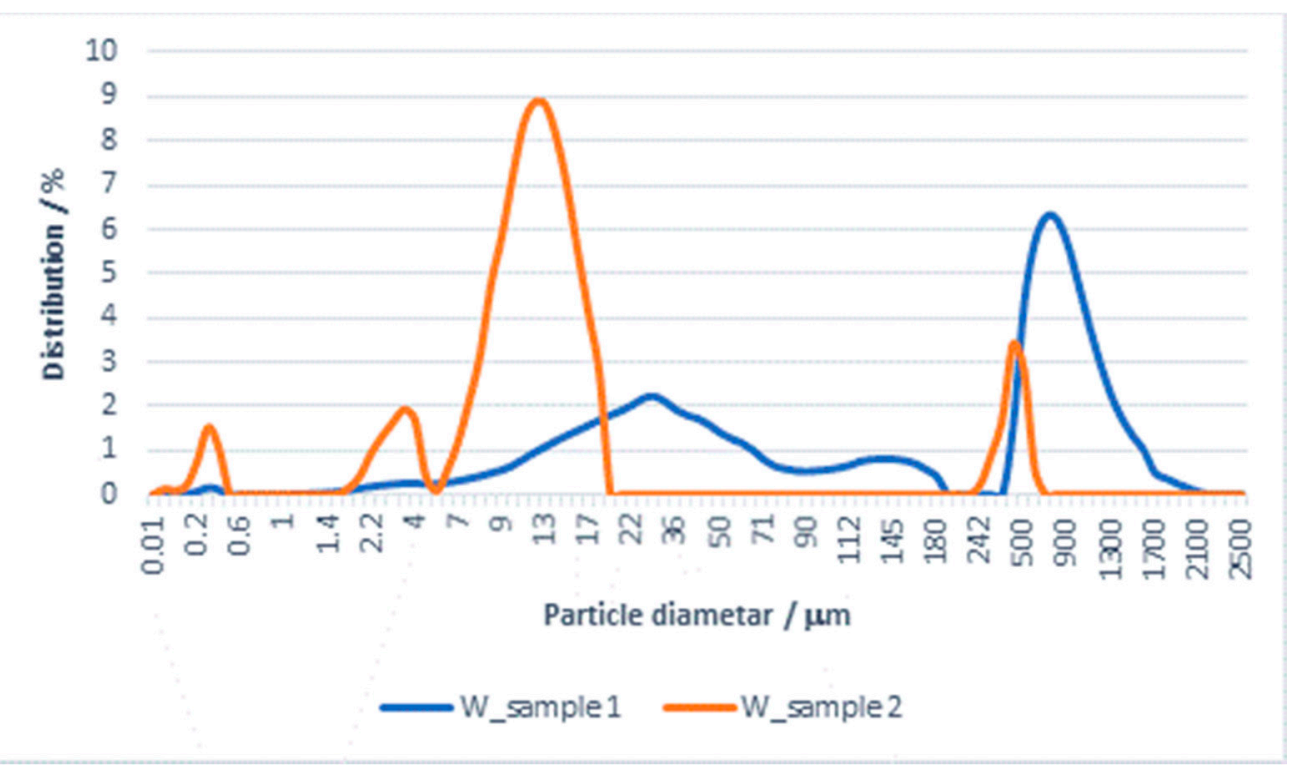

Figure 4. Distribution of particles (PSA) in the effluent from washing a cotton/PES fabric with water and subsequent rinsing.

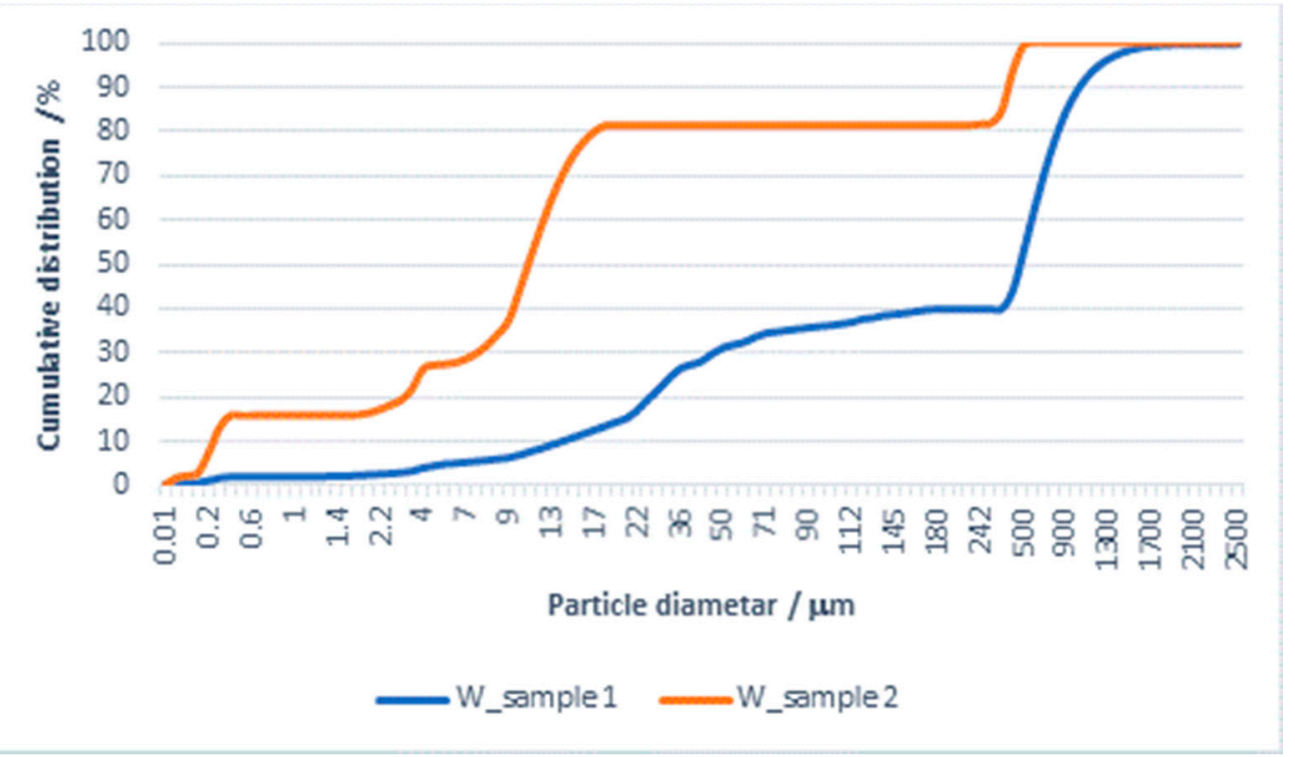

Figure 5. Cumulative distribution of particles (PSA) in the effluent from washing a cotton/PES fabric with water and subsequent rinsing.

Table 5. Results of volume-weighted D-value for effluents from washing in water and rinsing.

\begin{tabular}{llllll}
\hline Mean Value $/ \mu \mathrm{m}$ & $\mathrm{D}_{\mathbf{1 0}} / \boldsymbol{\mu m}$ & $\mathrm{D}_{\mathbf{5 0}} / \boldsymbol{\mu m}$ & $\mathrm{D}_{\mathbf{9 0}} / \boldsymbol{\mu m}$ & Mean Size/ $\boldsymbol{\mu m}$ & Span \\
\hline W_sample 1 & 14.726 & 439.013 & 998.805 & 482.899 & 2.243 \\
\hline W_sample 2 & 0.2378 & 10.527 & 352.498 & 77.033 & 33.467 \\
\hline
\end{tabular}

The PSA results for effluents from washing with water and subsequent rinsing show that both samples belong to polydisperse systems, with the mean particle size and all the presented diameters being significantly smaller for the samples of water from rinsing.

By comparing these values with the values obtained for the effluent from washing with detergent, significant differences can be observed. There is also a major difference in the mean value of the particles (mean size) in the effluent from washing in water $(482.899 \mu \mathrm{m})$ in relation to the effluent from rinsing, where it is $77.033 \mu \mathrm{m}$. The Span values, calculated 
according to Equation (3) for both samples, indicate differences in the distribution of particles by diameter; for the effluent from washing it is 2243 , whereas for the effluent from rinsing it is 33.467. The migration of particles in the processes of washing and rinsing in water can, in a certain way, be associated with the material surface and, in these effluents, can be characterized as particles of textile origin.

The factors of the Sinner's circle in the observed disperse washing and rinsing systems are different. In the process of washing the fabric with detergent, the chemical effect takes place through the action of its components (Table 1) in synergy with the mechanics through the reverse direction of rotation $60 / 60$ with $40 \mathrm{RPM}$ in a bath at $90^{\circ} \mathrm{C}$ for $30 \mathrm{~min}$.

The process of washing the fabric with water takes place with the same mechanics, temperature and time, while the interaction of the bath with the material takes place in water, without chemical effects of detergent. It is known that in such detergent-free washing systems the influence of mechanics, time, and temperature is dominant [7]. The indicators of the distribution of released particles show that higher temperature and mechanical agitation in the washing process contributed to a more significant release of particles.

After the washing process in detergent and water, the rinsing process was carried out through five cycles in a laboratory beaker, by gently stirring the sample in water at $20^{\circ} \mathrm{C}$ for $3 \mathrm{~min}$. Thus, the results of the particle diameter analysis indicate the migration of particles completely from the cotton/PES fabric into the effluent.

The importance of the Sinner's circle parameters [7] in the washing process and their interrelationship implies the need for conducting more advanced analyses to better define their influence on the degree of effluent load. In view of the observed disperse system in which particles are from different sources (detergent and material) and different geometric forms (particles and fibrils), it is important to group the parameters and define their interrelationship in the process of washing and rinsing. To obtain important additional information about the observed system, cluster analysis was performed. To perform these analyses, the data of the volume distribution were used, Figure 6.

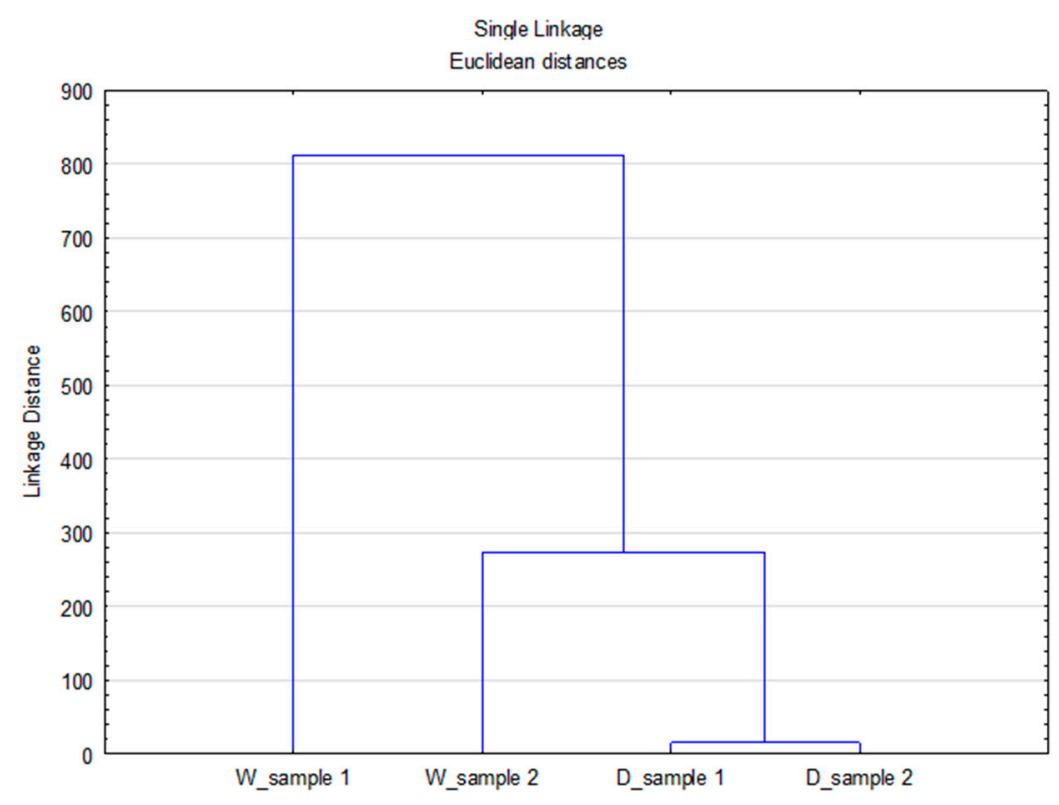

Figure 6. Dendogram of the CA with Linkage Distances of all data sets of volume distribution particles.

The obtained Linkage Distance values indicate the differences between the observed systems through the separation of one effluent (W_sample 1) into a separate group from the other effluents. The potentially released particles in this effluent originate exclusively from the previously highlighted Sinner's circle parameters (temperature, mechanics, and time) and can be geometrically characterized as fibrils. In the next group there is the effluent from rinsing (W_sample 2) followed by a group consisting of two effluents from washing 
with detergent (D_sample 1) and rinsing (D_sample 2). The presented Linkage Distance for these groups indicates some smaller differences in effluents, which can be attributed to the composition of the bath, dominated by detergent particles with a small proportion of particles with fibril geometry, which was confirmed by separating effluent W_sample 2 into a separate group.

A cluster analysis of the data sets of volume, surface, and number distributions for different $\mathrm{D}$ values was performed, Figures 7-9.

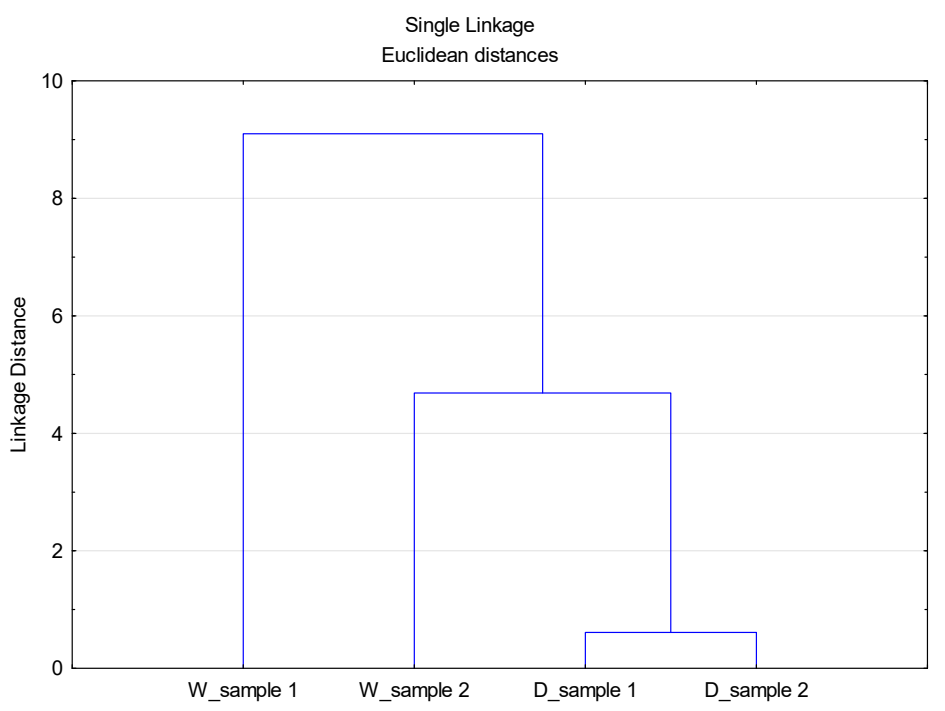

Figure 7. Dendogram of the CA with Linkage Distances of all data distribution sets for diameter $\mathrm{D}_{10}$.

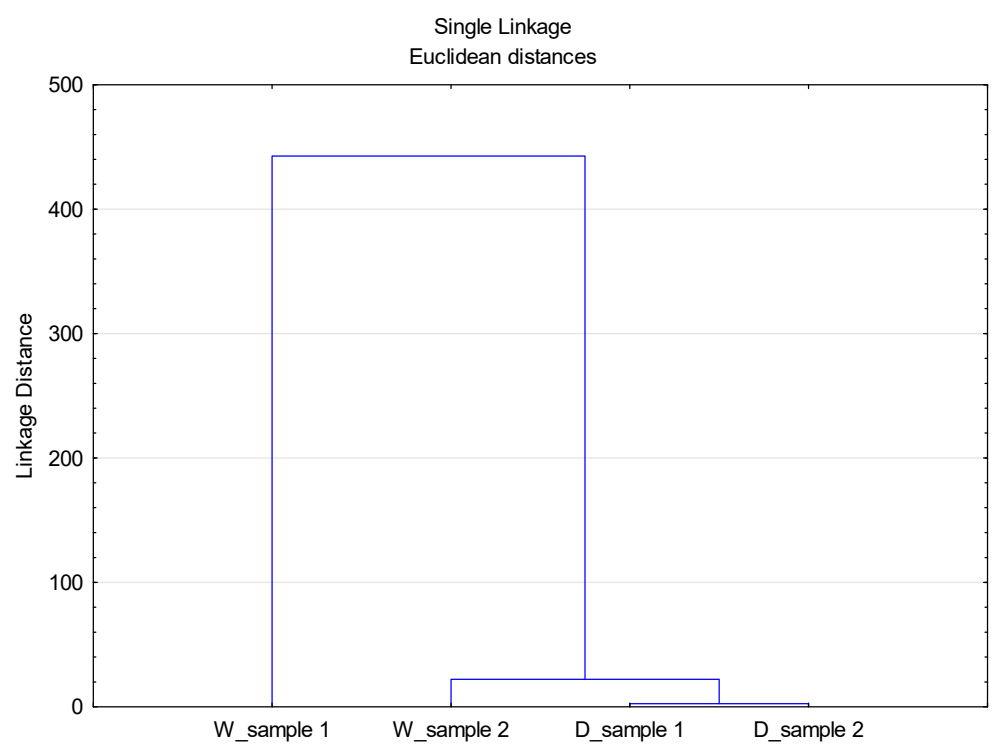

Figure 8. Dendogram of the CA with Linkage Distances of all data distribution sets for diameter $\mathrm{D}_{50}$. 


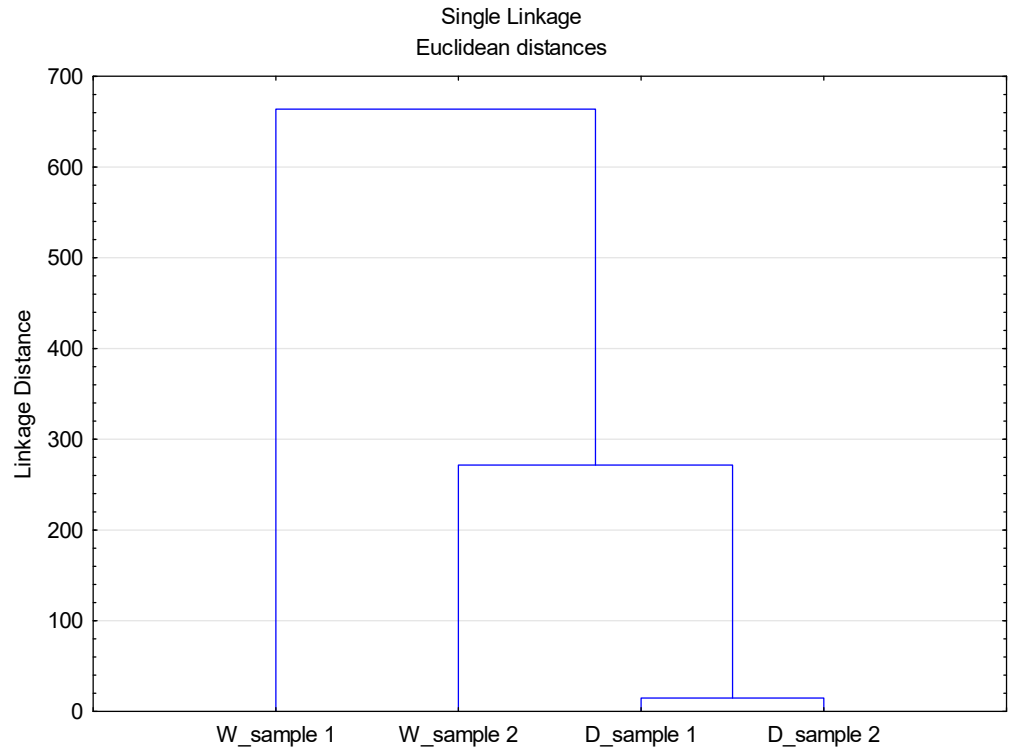

Figure 9. Dendogram of the CA with Linkage Distances of all data distribution sets for diameter $\mathrm{D}_{90}$.

As can be seen from Figures 7-9, the previously stated thesis about the source of particles in the observed system is confirmed. The Linkage Distance of the observed effluents is significantly smaller for particles of smaller diameter $\left(D_{10}\right)$ compared to diameter $D_{50}$ and diameter $\mathrm{D}_{90}$.

The examination of fabric and solid residues on filter after staining by digital microscope is shown in Figure 10.

The digital images of particular sections of the filter magnified $50 \times$ and $230 \times$ in Figure 10 show the different compositions of the residues. The roughness in the filter surface of D_sample 1 and D_sample 2 is affected by detergent residues with fibrillar fragments integrated into the matter contents. The comparison of the images of D_sample 2 and D_sample 1 shows a low rough filter surface of D_sample 2. At the same time, the fibril content in D_sample 2 is more obvious than in D_sample 1.

The filter content in W_sample 1 and W_sample 2 is mostly covered by fibrils, whereas the $W \_s a m p l e ~ 2$ is characterized by grouped fibrils in comparison to the W_sample 1.

The fabric in crepe weave was made from fine warp threads of cotton with polyester and the coarse weft threads just from cotton. The technical characteristics of the threads caused specific distribution of cotton and polyester fibrils as filter content, especially in D_sample 2 and W_sample 2, where cotton fibrils are blue stained. Polyester fibrils retained a pristine colorless form. 
Fabric
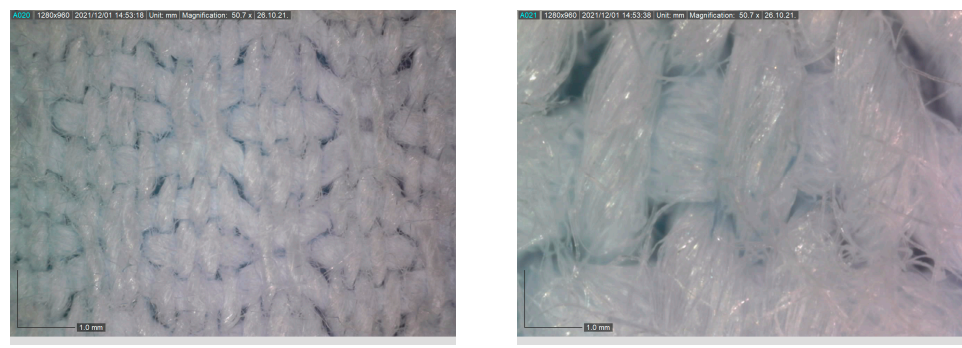

Effluents

Filter residues

D_sample 1
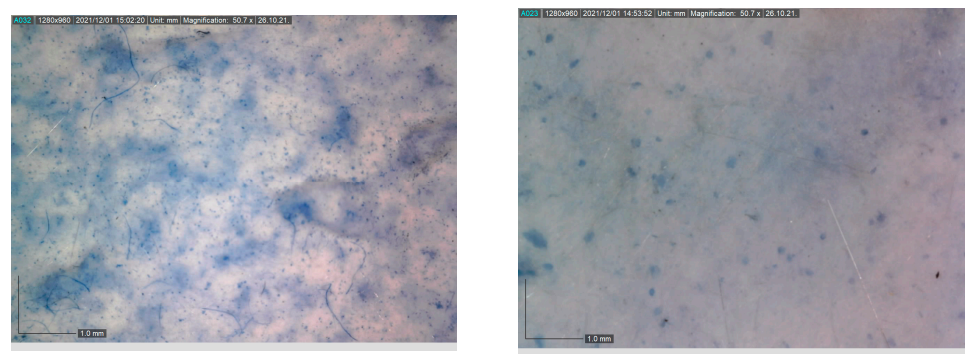

W_sample 1
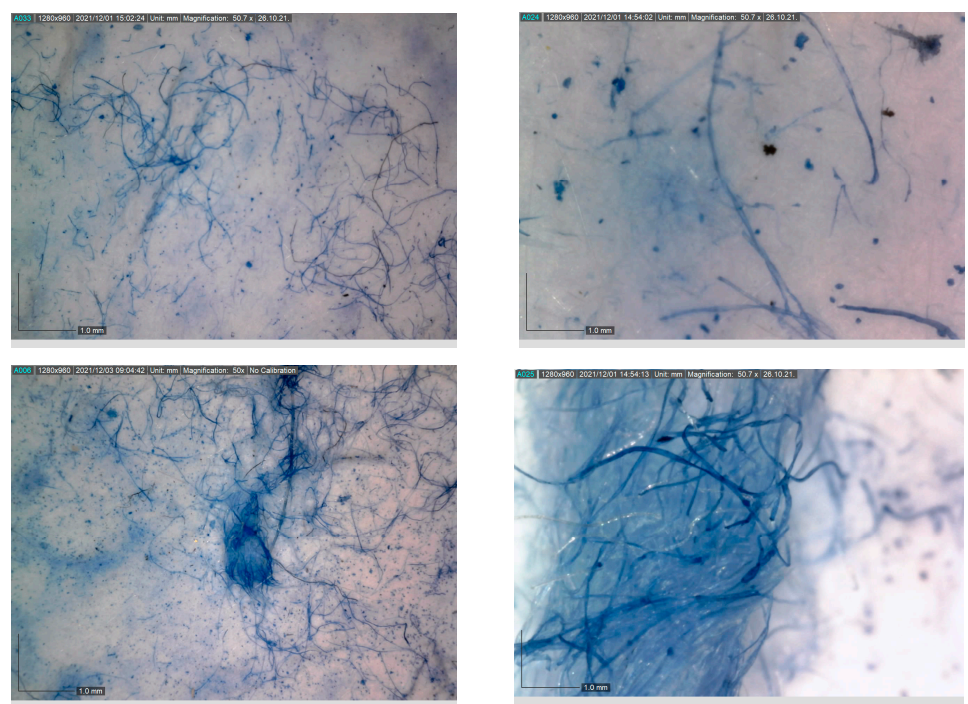

D_sample 2

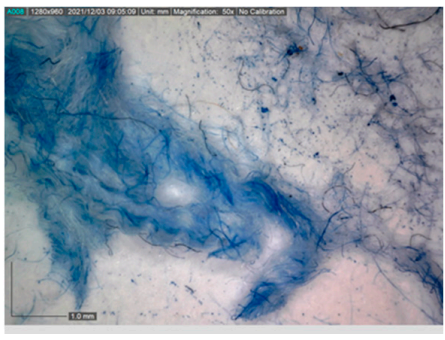

(a)

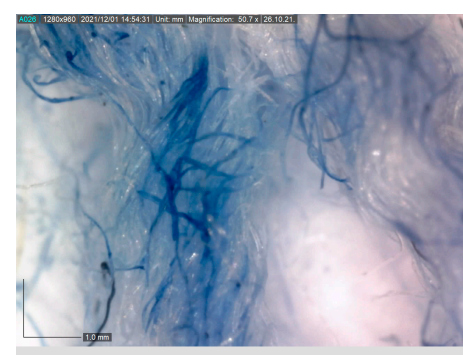

(b)

Figure 10. Digital images of stained and non-stained solid residues: (a) magnified $50 \times$; (b) magnified $230 \times$.

\section{Conclusions}

The results of the analysis of effluents from the washing and rinsing process of cotton/PES fabrics by the laser diffraction method contribute to the characterization of migrating and released particles, and point to the importance of observing their source and specific geometry. The specific geometry of the released particles, observed in the digital images, is due to the structure and composition of the fabric as well as the action of the detergent and the parameters of the washing and rinsing process. A complex 
dispersion system consisting of material, detergent, water, and the influence of Sinner's circle parameters requires the application of advanced statistical analyses. The results of the analysis provided an additional understanding of the interrelationships in the observed complex system, especially through the classification into groups based on process phases and characteristic diameters.

Author Contributions: Conceptualization, T.P., M.Č., B.V. and N.D.; investigation, T.P., M.Č. and B.V.; data curation: M.Č.; writing, review and editing: T.P. and M.Č. All authors have read and agreed to the published version of the manuscript.

Funding: This research has been fully supported by Croatian Science Foundation under the project IP-2020-02-7575 Assessment of microplastic shedding from polyester textiles in washing process.

Institutional Review Board Statement: Not applicable.

Informed Consent Statement: Not applicable.

Data Availability Statement: The data are open available.

Conflicts of Interest: The authors declare no conflict of interest.

\section{References}

1. Sait, S.T.L.; Sørensen, I.; Kubowicz, S.; Vike-Jonas, K.; Gonzalez, S.V.; Asimakopoulos, A.G.; Booth, A.M. Microplastic fibres from synthetic textiles: Environmental degradation and additive chemical content. Environ. Pollut. 2021, 268, 115745. [CrossRef] [PubMed]

2. Balasaraswathi, S.R.; Rathinamoorthy, R. Effect of fabric properties on microfiber shedding from synthetic textiles. J. Text. Inst. 2021, 1-21. [CrossRef]

3. Özkan, I.; Gündoğdu, S. Investigation on the microfiber release under controlled washings from the knitted fabrics produced by recycled and virgin polyester yarns. J. Text. Inst. 2021, 112, 264-272. [CrossRef]

4. Zhang, Y.-Q.; Lykaki, M.; Taher Alrajoula, M.; Markiewicz, M.; Kraas, C.; Kolbe, S.; Klinkhammer, K.; Rabe, M.; Klauer, R.; Bendtd, E.; et al. Microplastics from textile origin-Emission and reduction measures. Green Chem. 2021, 23, 5247-5271. [CrossRef]

5. De Falco, F.; Di Pace, E.; Cocca, M.; Avella, M. The contribution of washing processes of synthetic clothes to microplastic pollution. Sci. Rep. 2019, 9, 6633. [CrossRef]

6. Gaylarde, C.; Baptista-Neto, J.A.; Monteiro da Fonseca, E. Plastic microfibre pollution: How important is clothes' laundering? Heliyon 2021, 7, e07105. [CrossRef]

7. Kolbe, S. Mikroplastika ili mikrovlakna?-Koncepcijska zabuna. Tekstil 2018, 67, 235-236. (In Croatia)

8. Smulders, E.; Rähse, W.; Gunter, J. Laundry Detergents; Wiley VCH: Weinheim, Germany, 2002; ISBN 978-3527305209.

9. Ding, D.; Chen, L.; Dong, S.; Chai, H.; Chen, J.; Jiang, C.; Cai, T. Natural ageing process accelerates the release of Ag from functional textile in various exposure scenarios. Sci. Rep. 2016, 6, 37314. [CrossRef]

10. Farkas, J.; Peter, H.; Christian, P.; Urrea, J.A.G.; Hassellöv, M.; Tuoriniemi, J.; Gustafsson, S.; Olson, E.; Hylland, K.; Thomas, K.V. Characterization of the effluent from a nano silver producing washing machine. Environ. Int. 2011, 37, 1057-1062. [CrossRef]

11. Lorenz, C.; Windler, L.; Goetz, N.; Lehmann, R.P.; Schuppler, M.; Heuberger, K.; Heuberger, M.; Nowack, B. Characterization of silver release from commercially available functional (nano)textiles. Chemosphere 2012, 89, 817-824. [CrossRef] [PubMed]

12. Liu, H.; Gong, R.H.; Pinghua, X.; Ding, X.; Wu, X. The mechanism of wrinkling of cotton fabric in a front-loading washer: The effect of mechanical action. Text. Res. J. 2019, 89, 3802-3810. [CrossRef]

13. Hartline, N.L.; Bruce, N.J.; Karba, S.N.; Ruff, E.O.; Sonarand, S.U.; Holden, P.A. Microfibre masses recovered from conventional machine washing of new or aged garments. Environ. Sci. Technol. 2016, 50, 11532-11538. [CrossRef] [PubMed]

14. Abbasi, S.; Soltani, N.; Keshavarzi, B.; Moore, F.; Turner, A.; Hassanaghaei, M. Microplastic in different tissue of fish and prawn from the Musa Estuary. Persian Gulf. Chemosphere 2018, 205, 80-87.

15. Beverley, H.; Laitala, K.; Klepp, I.G. Microfibres from apparel and home textiles: Prospects for including microplastics in environmental sustainability assessment. Sci. Total Environ. 2019, 652, 483-494.

16. Marielis, C.; Zambrano, J.; Pawlaka, J.; Jesse Daystar, J.; Mary Ankeny, M.J.; Cheng, J. Microfibers generated from the laundering of cotton, rayon and polyester based fabrics and their aquatic biodegradation. Mar. Pollut. Bull. 2019, 142, $394-407$.

17. Haap, J.; Classen, E.; Beringer, J.; Mecheels, S.; Gutmann, J.S. Microplastic Fibers Released by Textile Laundry: A New Analytical Approach for the Determination of Fibers in Effluents. Water 2019, 11, 2088. [CrossRef]

18. Arshad, K.; Skrifvars, M.; Vivod, V.; Valh, J.; Voncina, B. Biodegradation of natural textile materials in soil. Tekstilec 2014, 57, 118-132. [CrossRef]

19. Dulekgurgen, E.; Dogruel, S.; Karahan, O.; Orhon, D. Size distribution of wastewater COD fraction as an index for biodegradability. Water Res. 2006, 40, 278-283. [CrossRef]

20. Sophonsiri, C.; Morgrnroth, E. Chemical composition associated with different particle size fractions in municipal, industrial, and agricultural wastewaters. Chemosphere 2004, 55, 691-703. [CrossRef] 
21. Beek, C.G.E.M.V.; Zwart, A.H.D.; Balemans, M.; Kooiman, J.W.; Rosmalen, C.V.; Timmer, H.; Vandersluys, J.; Stuyfzand, P.J. Concentration and size distribution of particle in abstracted groundwater. Water Res. 2010, 44, 868-878. [CrossRef]

22. Arimi, M.M.; Namango, S.S.; Goetz, G.; Zhang, Y.; Kiriamiti, K.; Geissen, S.U. The abrasion effect of natural organic particles on membrane permeability and the size distribution of recalcitrant in colored effluent. J. Membr. Sci. 2016, 509, 1-9. [CrossRef]

23. Ravndal, K.T.; Opsahl, E.; Bagi, A.; Kommedal, R. Wastewater characterization by combining size fractionation, chemical composition, and biodegradability. Water Res. 2018, 131, 151-160. [CrossRef]

24. Hargreaves, A.J.; Vale, P.; Whelan, J.; Alibardi, L.; Constantino, C.; Dotro, G.; Carmell, E.; Campo, P. Impacts of coagulationflocculation treatment on the size distribution and bioavailability of trace metals $(\mathrm{Cu}, \mathrm{Pb}, \mathrm{Ni}, \mathrm{Zn})$ in municipal wastewater. Water Res. 2018, 128, 120-128. [CrossRef]

25. Dogruel, S.; Olmez-Hanci, T.; Kartal, Z.; Arslan-Alaton, I.; Orhon, D. Effect of Fenton s oxidation on the particle size distribution of organic carbon in olive mill wastewater. Water Res. 2009, 43, 3974-3983. [CrossRef] [PubMed]

26. Halstead, J.E.; Smith, J.A.; Carter, E.A.; Lay, P.A.; Johnston, E.L. Assessment tools for microplastic and natural fibres ingested by fish in an urbanized estuary. Environ. Pollut. 2018, 234, 552-561. [CrossRef] [PubMed]

27. Muller, J.N.; Muller, J.C. Statistics and Chemometrics for Analytical Chemistry, 6th ed.; Prentice Hall: Hoboken, NJ, USA, 2010; ISBN-13 978-0273730422.

28. International Organization for Standardization (ISO). ISO 9276-2: Representation of Results of Particle Size Analysis—Part 2: Calculation of Average Particle Size/Diameters and Moments from Particle Size Distributions; International Organization for Standardization (ISO): Geneva, Switzerland, 2014. 